\title{
Components of Glial Responses to Exogenous and Synaptic Glutamate in Rat Hippocampal Microcultures
}

\author{
Steven Mennerick, ${ }^{3}$ Ann Benz, ${ }^{1}$ and Charles F. Zorumski ${ }^{1,2}$ \\ Departments of ${ }^{1}$ Psychiatry and ${ }^{2}$ Anatomy and Neurobiology, and ${ }^{3}$ Program in Neuroscience, Washington University \\ School of Medicine, St. Louis, Missouri 63110
}

\begin{abstract}
Although glia are known to be sensitive to exogenously applied neurotransmitter substances, little is known about how glia respond to neuronal activity on the millisecond time scale of individual synaptic events. We have explored the electrophysiological effects of excitatory neuronal signaling on glial cells in rat hippocampal microcultures. Exogenous applications of glutamate analogs to islands of glia revealed a large ionotropic AMPA receptor-mediated current and a smaller current mediated by electrogenic glutamate uptake. Glia demonstrated no evidence of NMDA or metabotropic receptor-mediated currents or membrane conductance changes. Despite the dominant contribution of AMPA receptors to exogenous glutamate
\end{abstract}

applications in glia, AMPA receptor currents contributed only $\sim 20 \%$ to the response of glia to endogenous glutamate release from solitary excitatory neurons. Electrogenic glutamate uptake contributed strongly to glial responses to neuronal stimulation. In addition, some glia exhibited a residual current in response to neuronal stimulation that was not attributable to calciumdependent transmitter release or to neuronal potassium efflux. These results help provide a context for understanding the role of glial transporters and receptors in nervous system signaling.

Key words: AMPA receptors; glutamate uptake; astrocytes; EPSC; hippocampus; microculture
The intimate association of neurons and astrocytes in the central nervous system suggests the existence of complex neuron-to-glia and glia-to-neuron signaling. Recent optical and electrophysiological recording techniques applied to astrocytes have revealed the presence of functional ligand-gated and second messengerlinked transmitter receptors in culture and in situ (Sontheimer et al., 1988; Usowicz et al., 1989; Cornell-Bell et al., 1990; Müller et al., 1992). Also, changes in glial intracellular calcium, apparently mediated by activity-dependent glutamate release (Dani et al., 1992), and slow glial membrane depolarizations, probably mediated by extracellular potassium rise (Orkand et al., 1966; Ransom and Goldring, 1973), can begin several seconds after repetitive neuronal stimulation. Although these results indicate that glia can be responsive to neuronal activity, the electrophysiological effects on glia of single neuronal action potentials and subsequent release of endogenous transmitter have only begun to be understood (Murphy et al., 1993).

Microcultures (Furshpan et al., 1986) of central nervous system cells offer a convenient and powerful experimental preparation for the study of interactions between neurons and glia on the millisecond time scale of single action potentials and synaptic events. The physical constraints of microcultures on neuronal and glial outgrowth allow the exploration of electrophysiological interactions and signaling between these cell types in a manner that

\footnotetext{
Received Aug. 21, 1995; revised Sept. 11, 1995; accepted Sept. 13, 1995.

This work was supported by National Institutes of Health Research Scientist Development Award MH-00964, Grants MH-45493 and AG-11355, and a fellowship from the Bantly Foundation. We thank Jian Que for technical assistance with computer programs and Yuki Izumi, Liu Lin Thio, Keith Isenberg, and Lisa Wittmer for helpful discussion.

Correspondence should be addressed to Dr. Charles F. Zorumski, Department of Psychiatry, Washington University School of Medicine, 4940 Children's Place, St. Louis, MO 63110.

Dr. Mennerick's current address: Department of Neurobiology and Behavior, State University of New York at Stony Brook, Stony Brook, NY 11794.

Copyright (C) 1995 Society for Neuroscience $0270-6474 / 95 / 160055-10 \$ 05.00 / 0$
}

would be difficult in other culture preparations or in more intact preparations. Previous work from this laboratory has shown that electrogenic glutamate transport participates in the responses of glial cells to neuronal stimulation in hippocampal microcultures (Mennerick and Zorumski, 1994). However, inhibitors of glutamate uptake fail to abolish glial responses to neuronal activity (Mennerick and Zorumski, 1994). This may indicate that glial responses comprise more than a single component. To explore this possibility, we investigated the responses of hippocampal microculture glia to exogenously applied glutamate analogs, and we have explored further the pharmacology of glial responses to stimulation of solitary excitatory neurons.

\section{MATERIALS AND METHODS}

Cultures. Microisland cultures were prepared as described previously (Mennerick et al., 1995). Sprague-Dawley rat pups (1-3 d postnatal) were anesthetized with halothane and decapitated. Hippocampal slices 500 $800 \mu \mathrm{m}$ thick were prepared and treated with $1 \mathrm{mg} / \mathrm{ml}$ papain in oxygenated Leibovitz's L-15 medium. Slices were gently triturated in modified Eagle's medium containing 5\% horse serum, 5\% fetal calf serum, $17 \mathrm{~mm}$ $\mathrm{D}$-glucose, $400 \mu \mathrm{M}$ glutamine, $50 \mathrm{U} / \mathrm{ml}$ penicillin, and $50 \mu \mathrm{g} / \mathrm{ml}$ streptomycin. A single cell suspension $(\sim 20,000 \mathrm{cells} / \mathrm{ml})$ was plated on plastic culture dishes $(35 \mathrm{~mm}$ diameter) treated with a layer of agarose $(0.15 \%)$ and collagen droplets $(0.5 \mathrm{mg} / \mathrm{ml}$ rat tail, Sigma Type I) as described previously (Mennerick et al., 1995). After $3 \mathrm{~d}$ in culture, all cells were treated with $10 \mu \mathrm{M}$ cytosine arabinoside to halt glial proliferation. Cells were used for experiments 5-16 d after plating. Synaptic studies usually were performed on cells $\geq 10 \mathrm{~d}$ in vitro.

Solutions and drugs. The extracellular recording solutions consisted of (in $\mathrm{mM}$ ): $138 \mathrm{NaCl}, 4 \mathrm{KCl}, 10 \mathrm{HEPES}$, and 10 glucose. Unless otherwise stated, extracellular solutions contained $3 \mathrm{mM} \mathrm{CaCl}_{2}$ and $1 \mathrm{~mm} \mathrm{MgCl}$. Osmolarity was maintained at $310 \mathrm{mOsm}$ by addition of sucrose, and $\mathrm{pH}$ was adjusted to 7.25 with $\mathrm{NaOH}$. For synaptic studies, D-amino-5-phosphonovaleric acid (D-APV) was present at $30-50 \mu \mathrm{M}$ to block contributions of NMDA receptors to synaptic currents. Drugs were applied by one of two methods. For examination of the rapidly desensitizing component of glutamate currents, a gravity-driven linear flow-tube array was used that allowed solution cxchanges in $-10 \mathrm{mscc}$ on whole cells (Zorumski ct al., 1993). For synaptic studies and for slow drug applications, a gravity- 
driven multibarrel pipette with a common tip opening was used. This system allowed $10-90 \%$ exchanges in $-200 \mathrm{mscc}$, which wcre asscsscd with junction potential changes at the tip of an open patch pipette.

Pipette solutions used for neuronal and glial cell recordings usually contained (in mM): 140 potassium gluconate, $4 \mathrm{NaCl}, 0.5 \mathrm{CaCl}_{2}, 5 \mathrm{EGTA}$, 2 magnesium ATP, 0.5 sodium GTP, $10 \mathrm{HEPES}$, pH-adjusted to 7.25 with $\mathrm{KOH}$. For some experiments examining glial responses to exogenous agonists (see Figs. 1,2), a cesium chloride pipette solution was used (in $\mathrm{mM}$ ): $140 \mathrm{CsCl}, 4 \mathrm{NaCl}, 0.5 \mathrm{CaCl}_{2}, 5$ EGTA, $4 \mathrm{MgCl}_{2}, 10$ HEPES, $\mathrm{pH}$-adjusted to 7.25 with $\mathrm{CsOH}$.

All chemicals and drugs for experiments were from Sigma (St. Louis, MO) except D-APV (Cambridge Research Biochemicals, Wilmington, $\mathrm{DE}$ ), 2,3-dihydroxy-6-nitro-7-sulfamoyl-benzo $(F)$ quinoxaline (NBQX; gift of Dr. John Olney, Washington University), cyclothiazide (CYZ; gift of Lilly Pharmaceuticals, Indianapolis, IN), GYKI-52466 (gift of Dr. I. Tarnawa, Institute for Drug Research, Budapest, Hungary), and AMPA (Tocris Cookson, Bristol, UK). NBQX, GYKI-52466, and CYZ were stored as concentrated stock solutions in dimethylsulfoxide. All solutions in experiments using these drugs were routinely matched for final dimethylsulfoxide concentration, which was $\leq 0.2 \%$.

Recordings. Neurons were stimulated and monitored using the discontinuous single-electrode voltage-clamp mode of an Axoclamp 2-A amplifier with $10-11 \mathrm{kHz}$ switching frequency. Stimulation of cells was achieved with a $1.5 \mathrm{msec}$ voltage step to $+20 \mathrm{mV}$ (from a holding potential of $-70 \mathrm{mV}$ ). Glia were monitored using an Axopatch 1-D or EPC-7 patch clamp amplifier, usually at a holding potential of $-70 \mathrm{mV}$. Currents were filtered at $2 \mathrm{kHz}$ and digitized at $3-5 \mathrm{kHz}$, except for fluctuation analysis experiments. For fluctuation analysis, two channels representing the DC current and the AC-coupled signal were collected at full bandwidth to a VHS videotape ( $44 \mathrm{kHz} /$ channel sample rate) for later analysis. For fluctuation analysis experiments, agonist applications were $15-30 \mathrm{sec}$ in duration and control periods were of the same duration. All experiments were performed at room temperature $\left(20-25^{\circ} \mathrm{C}\right)$.

Exogenous applications of glutamate analogs were made to both populated (neuron-containing) and unpopulated microcultures. No systematic differences in responses to any agonists were noted, so results from both types of microcultures were pooled. Dual recordings were made from glia and neurons on microcultures populated by a single neuron, identified with phase contrast microscopy.

Analysis. During experiments, evoked responses were collected to computer disk for analysis. Analysis was performed using averaging and analysis programs written in Axobasic (Axon Instruments, Foster City, CA) or using Clampfit analysis routines (pClamp 5.51, Axon Instruments). Fits of dose-response relationships and exponential decays were performed using least-squares minimization routines. Dose-response data were fit using the equation $I=I_{\max }\left[C^{n} /\left(C^{n}+\mathrm{EC}_{50}^{n}\right)\right]$, where $I$ is the response, $I_{\max }$ is the maximum response, $\mathrm{EC}_{50}$ is the half-maximal effective concentration, $C$ is agonist concentration, and $n$ is the Hill coefficient. Unless otherwise specified, results are expressed as mean \pm SE. Percent changes were calculated by subtracting 1 from the ratio of experimental to control responses. Therefore, negative percent changes reflect depression and positive values reflect potentiation. In the figures, responses to exogenous drugs are typically a single representative response, whereas evoked autaptic currents and associated glial responses are usually the average of two to five responses.

For fluctuation analysis, both the DC- and the AC-coupled signals were sampled at $1 \mathrm{kHz}$ from a VHS videotape with Axotape software (Axon Instruments) through an 8-pole Bessel (DC current) or 8-pole Butterworth (AC-coupled signal) low-pass filter $(500 \mathrm{~Hz} / \mathrm{channel})$. Analysis of power spectra was performed using software written in Axobasic. Power spectra for AMPA-induced current fluctuations were obtained by subtracting spectra obtained in the absence of AMPA from spcetra obtaincd in the presence of agonist. Net spectra for AMPA were fitted with a single Lorentzian function of the form $S(f)=S(0) /\left(1+\left(f / f_{c}\right)^{2}\right)$, where $S(f)$ is the single-sided spectral density at frequency $f$ and $f_{\mathrm{c}}$ is the corner frequency, the frequency at which $S(f)$ is $0.5 S(0)$. In some neurons and glia, AMPA power spectra were better fit by the sum of two Lorentzian functions. Because there were no systematic differences between neurons and glia in this regard, we used results obtained with the best fit of a single Lorentzian function for comparison of the two cell types (Thio et al., 1992). Corner frequencies were converted to time constants by the equation $\tau=1 /\left(2 \pi f_{c}\right)$. Mean-variance plots were obtained by dividing the rising phase of AMPA currents into 8-15 equally spaced time bins and calculating the mean DC current and the variance for each bin. Single- channel currents were estimated from the slopes of linear regressions fitted to mean-variance plots.

Histology and electron microscopy. Cultures destined for electron microscopic evaluation were filled for 5-7 $\mathrm{min}$ with a whole-cell patch pipette solution containing the above potassium gluconate solution with $0.2 \%$ biocytin added. After removal of the patch pipette but before fixation with $2 \%$ glutaraldehyde in phosphate-buffered saline, biocytin was allowed to fill neuronal processes for $1 \mathrm{hr}$. Biocytin visualization was achieved using a 30 min treatment with $0.01 \%$ Triton $X$ detergent followed by development using an avidin-biotin-peroxidase method with diaminobenzidine hydrochloride as the peroxidase substrate (ABC Elite kit, Vector Laboratories, Burlingame, CA). Cultures were then dehydrated, osmicated ( $2 \%$ osmium tetroxide), embedded in araldite plastic, and sectioned perpendicular to the bottom of the culture dish. Sections were lightly stained with uranyl acetate $(3 \mathrm{~min})$ and lead citrate $(1.5 \mathrm{~min})$ and were examined with a JEOL JEM 100B transmission electron microscope.

\section{RESULTS}

As a guide to understanding excitatory neuronal effects on glial cells in the vertebrate central nervous system, we first examined the effects of exogenous glutamate analogs on hippocampal glial microculturcs. Microislands of glia responded to rapid flow-tube applications of glutamate with rapidly desensitizing currents characteristic of non-NMDA ionotropic receptor channels (Fig. 1). Consistent with the glial receptors belonging to the AMPApreferring class of glutamate receptors (Keinanen et al., 1990), glia exhibited rapidly desensitizing responses to AMPA and glutamate applications (Fig. $1 A, E$ ) but exhibited nondesensitizing currents in response to kainate applications (Fig. $1 B$ ). Whole-cell macroscopic desensitization to $1 \mathrm{~mm}$ glutamate in glia occurred with a time constant of $12.4 \pm 0.5 \mathrm{msec}(n=31)$, whereas in a sample of microculture neurons the time constant was $15.2 \pm 1.0$ msec $(n=15)$. Although these values allow neuronal and glial responses to be compared under similar experimental conditions, the time constants of desensitization are likely to be slowed artificially by limitations in drug delivery to whole cells. Fits of glutamate dose-response data (see Materials and Methods) yielded an $\mathrm{EC}_{50}$ for glia of $573 \mu \mathrm{M}$ for peak currents and $15 \mu \mathrm{M}$ for steady-state currents (data not shown), similar to values obtained in microculture hippocampal neurons (309 and $20 \mu \mathrm{M}$, data not shown).

Glutamate currents in Bergmann glia of the cerebellum have been shown to possess doubly-rectifying current-voltage curves characteristic of calcium-permeable AMPA receptors (Burnashev et al., 1992; Müller et al., 1992). In contrast, we found that hippocampal microislands of glia demonstrated the nearly linear current-voltage relationship typically associated with the presence of the GluRB AMPA receptor subunit (Fig. $1 C, D$ ) (Verdoorn et al., 1991). This current-voltage behavior is also typical of most neurons in hippocampal cultures in response to AMPA receptor activation (Thio et al., 1991).

AMPA receptors can vary in their sensitivity to cyclothiazide, a drug that potentiates agonist responses at AMPA receptors but not at kainate reccptors (Partin ct al., 1993). Ncurons in hippocampal cultures typically are highly sensitive to cyclothiazide (Yamada and Tang, 1993; Zorumski et al., 1993), perhaps indicating the presence of a flip subunit in most neuronal AMPA receptors (Partin et al., 1994). Hippocampal microculture glia also demonstrated a high sensitivity to cyclothiazide (Fig. 1E,F).

In addition to inducing changes in the average glial membrane current, AMPA receptor agonists increased membrane current fluctuations, consistent with the stochastic opening and closing of ion channels (Anderson and Stevens, 1973). We compared the properties of glial and neuronal current fluctuations by analyzing 


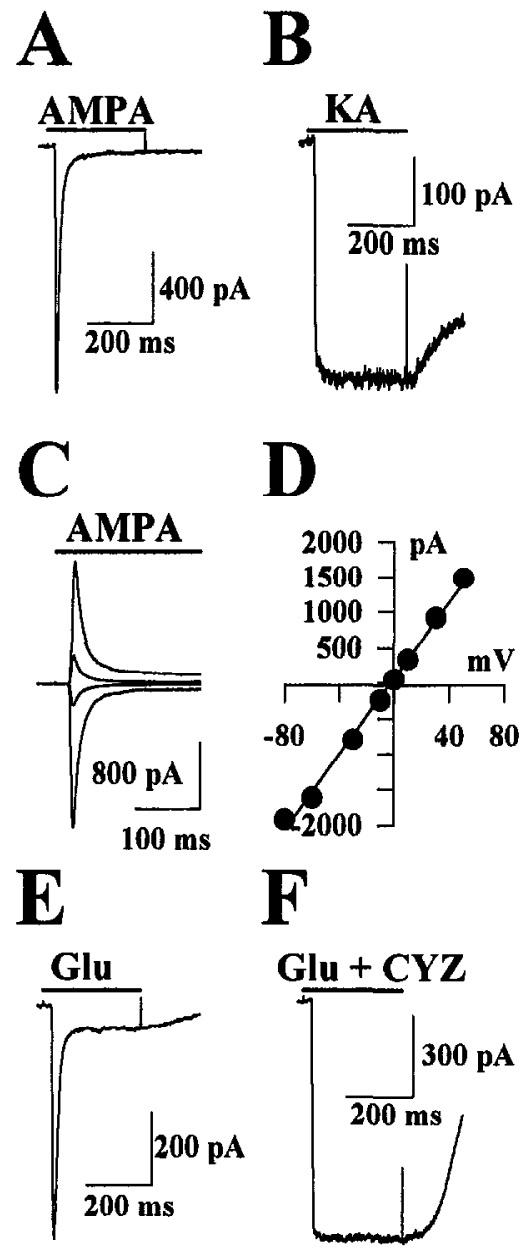

Figure 1. Microculture glia exhibit large ionotropic AMPA receptormediated currents. A, A 300 msec application of $1 \mathrm{mM}$ AMPA, indicated by the horizontal bar, induced a rapidly desensitizing current in a microculture glial cell. Upward spikes in this and subsequent figures are electrical artifacts caused by opening and closing of drug-delivery valves. $B$, In the same cell, $1 \mathrm{mM}$ kainate $(K A)$ induced a nondesensitizing current. $C$, $D$, AMPA responses show a linear current-voltage relationship. $C$, AMPA currents at glial membrane potentials of $-60,-10,+10$, and $+50 \mathrm{mV}$. Baseline holding currents have been subtracted. $D$, The symbols in the graph represent the peak AMPA current plotted against eight different holding potentials for the cell in $C$. The line represents a linear regression through the data points. $E, F$, Glial AMPA receptors are sensitive to cyclothiazide. $E$, Microisland to the application of $2 \mathrm{mM}$ glutamate $(\mathrm{Glu})$. $F$, Response of the same cell to glutamate $+\mathrm{CYZ}(25 \mu \mathrm{M})$ after pretreatment with CYZ alone. For all experiments in this figure, drugs were applied by flow tube and a cesium chloride pipette solution was used.

the power spectra of agonist-induced responses in the two cell types. Figure $2 A$ (top) shows a typical DC inward current induced by a slow application of $20 \mu \mathrm{M}$ AMPA to a glial cell voltageclamped at $-65 \mathrm{mV}$. The bottom trace shows a corresponding higher gain trace of the AC-coupled signal, revealing the increased current fluctuations induced by AMPA. Power spectra of AMPA-induced fluctuations were characterized by a corner frequency of $30.7 \pm 3.8 \mathrm{~Hz}$ in glial cells $(n=8$; Fig. $2 B$ ), and power spectra of neurons were characterized by a corner frequency of $30.0 \pm 3.0 \mathrm{~Hz}(n=9, p>0.8)$. These corner frequencies corresponded to time constants of $5.6 \pm 0.5 \mathrm{msec}$ for glia and 5.7 $\pm 0.5 \mathrm{msec}$ for neurons. Mean-variance plots obtained from the onset of AMPA currents were analyzed to obtain estimates of the mean single-channel current activated by agonist (Fig. 2C). Plots

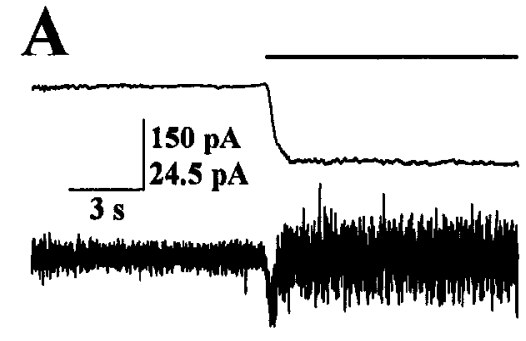

B
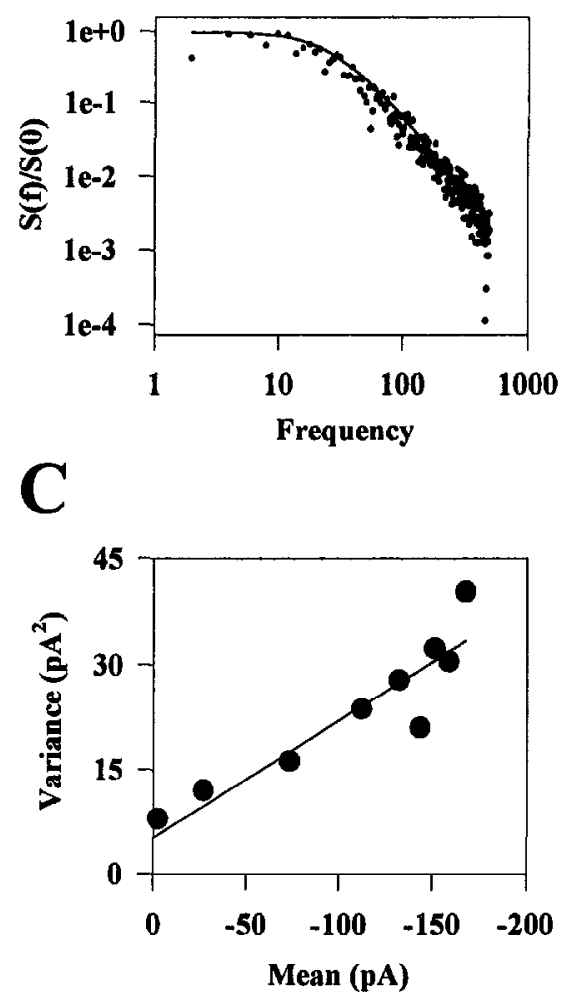

Figure 2, Fluctuation analysis of AMPA-induced currents in glia. $A$, The effect of slow application of $20 \mu \mathrm{M}$ AMPA on glial membrane current in a cell voltage-clamped at $-65 \mathrm{mV}$. The top refiects the DC current signal; the bottom is a higher-gain representation of the AC-coupled signal. The bar above the DC trace represents the duration of the AMPA application. $B$, The graph shows the power spectrum for the AMPA-induced increase in membrane current fluctuations shown in $A$. The difference spectrum shown here was obtained by subtracting the spectrum obtained in the absence of AMPA from the spectrum obtained in the presence of AMPA. The data were fitted by a single Lorentzian function $(-)$ (see Materials and Methods) characterized by a corner frequency of $26.0 \mathrm{~Hz}$. $C$, The graph shows a mean-variance plot for the onset of the AMPA current in $A$. The onset was divided into 10 equal time periods, for which the mean and variance of the current were calculated. The line represents a linear regression fit to the data with a slope of $0.17 \mathrm{pA}$.

for both glia and neurons were approximately linear, consistent with a low probability of channel opening. Slopes obtained from linear regressions fitted to mean-variance plots were $0.23 \pm 0.04$ $\mathrm{pA}$ for glia $(n=8)$ and $0.18 \pm 0.02 \mathrm{pA}$ for neurons $(n=9, p>$ $0.2)$. Results from the studies represented in Figures 1 and 2 suggest that in several respects, including agonist selectivity, desensitization, potentiation by cyclothiazide, and inferred singlechannel properties, glial AMPA receptors are very similar to neuronal AMPA receptors. 


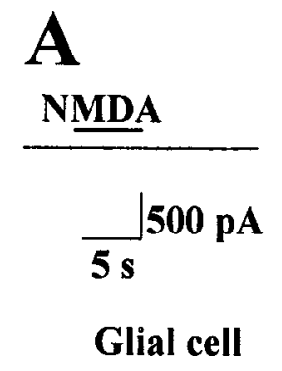

B $A$, Lack of response of a glial cell to application of 1 mM NMDA by multibarrel pipette. The external bath solution contained $2 \mathrm{mM} \mathrm{CaCl}, 0$ $\mathrm{mM} \mathrm{MgCl}$, and $20 \mu \mathrm{M}$ glycine. $B$, Response of a neuron from the same culture dish to the same application of NMDA. The scale hars in $A$ correspond to both panels. The pipette solution for both cells contained potassium gluconate.

To determinc whether other receptor types participate in glial responses to glutamate, we used selective agonists for the two other classes of glutamate receptor: NMDA and metabotropic receptors. In these experiments, we manipulated the extracellular and intracellular solutions to enhance detection of responses to these agonists. In addition, we explored the effects of the broadspectrum glutamate uptake substrate D,L-threo-3-hydroxyaspartate (THA), which induces electrogenic glutamate uptake currents in Müller cells of the retina (Barbour et al., 1991) and in cells expressing recombinant glutamate transporters (Arriza et al., 1994; Klockner et al., 1994).

Figure $3 A$ shows that microculture glia do not exhibit ionotropic currents mediated by NMDA receptors, in contrast to results in cerebellar Bergmann glia (Müller et al., 1993). No response to NMDA was observed in any of eight glia tested under the conditions of the experiment shown in Figure 3. In contrast, ncurons from the same culture plates exhibitcd large responses to NMDA under the same experimental conditions (Fig. 3B).

The metabotropic receptor agonist $1 S, 3 R$-amino-1,3-cyclopentanedicarboxylic acid (ACPD; $100 \mu \mathrm{M}$ ) also failed to induce a current in glia maintained at a holding potential of $-70 \mathrm{mV}$. In addition, during $200 \mathrm{msec}$ voltage steps from -70 to $-50 \mathrm{mV}$, no membrane conductance change was found during ACPD application. The input resistance of five glia calculated at the termination of the $20 \mathrm{mV}$ voltage step varied from 36 to $3000 \mathrm{M} \Omega$ (mean 700 $\pm 540 \mathrm{M} \Omega$ ). A $20 \mathrm{sec}$ application of ACPD decreased the input resistance of these cells by only $-4 \pm 6 \%$ ( $p>0.3$, paired $t$ test). From this sample of cells and from less formal observations, small glia with a single nucleus tended to have the highest input resistances, often $>1 \mathrm{G} \Omega$, whereas large or multi-nucleated microcultures had low input resistances, often $<50 \mathrm{M} \Omega$. The low input resistance of multinucleated microcultures is consistent with electrotonic coupling of type I astrocytes (Stephens et al., 1993; Belliveau and Naus, 1994; Enkvist and McCarthy, 1994).

In contrast to these negative results, THA induced currents in virtually all of the glial islands studied (Fig. 4). Although THA has been reported to gate NMDA currents in neurons directly (Tong and Jahr, 1994a), the current mediated by THA in glia was not an NMDA current; NMDA itself did not induce a current in the same cells in which THA induced a current $(n=8)$. Furthermore, THA currents were routinely recorded from glia in extracellular solutions containing millimolar concentrations of magnesium and $50 \mu \mathrm{M}$ D-APV.
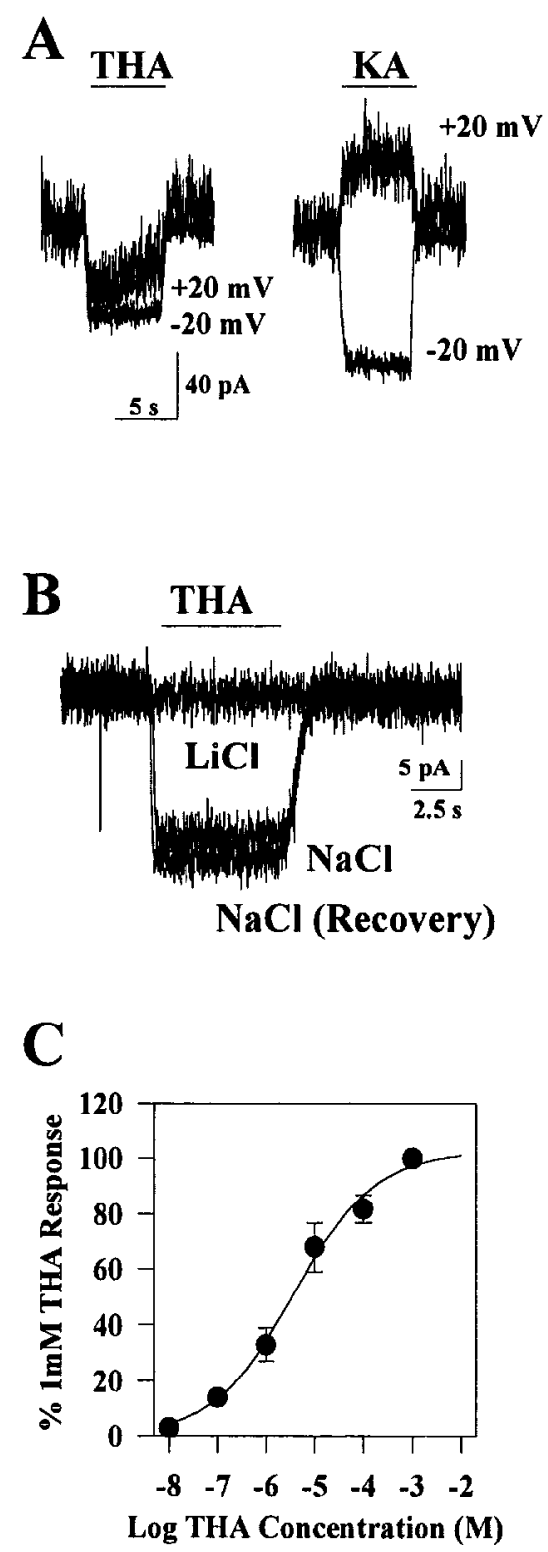

Figure 4. Microculture glia exhibit small electrogenic glutamate transporter currents. $A$, The transport substrate THA induces inward currents in glia. The left panel shows responses to $50 \mu \mathrm{M}$ THA in a microculture glial cell at -20 and $+20 \mathrm{mV}$. Note that the current remained inward at $+20 \mathrm{mV}$. The right panel shows responses of the same cell to applications of $50 \mu \mathrm{M}$ kainate. In contrast to THA, kainate elicited an outward current at $+20 \mathrm{mV}$. The extra noise in the currents at $+20 \mathrm{mV}$ was attributable to the activation of voltage-gated currents in the glial cell, typically seen when a potassium-containing pipette solution was used. Baseline holding current has been subtracted for display. $B$, THA currents are dependent on extracellular sodium. Traces depict responses to $50 \mu \mathrm{M}$ THA in normal sodium-containing extracellular solution and after total replacement of sodium with lithium. $C$, The graph shows the dose-response relationship for THA currents. The amplitude of inward current in response to varying THA concentrations is depicted by the symbols. Each point represents the response of 6-10 glia. Responses are normalized to the response of each cell to $1 \mathrm{~mm}$ THA. The line represents the best fit to the data of the equation $I=I_{\max }\left[C^{n} /\left(C^{n}+\mathrm{EC}_{50}^{n}\right)\right]$, where $I$ is the response, $I_{\max }$ is the maximum response, $\mathrm{EC}_{50}$ is the half-maximal response, $C$ is THA concentration, and $n$ is the Hill coefficient. The fit suggests an $\mathrm{EC}_{50}$ of $4 \mu \mathrm{M}$ and a Hill coefficient of 0.5 . The pipette solution for the experiments in Figure 3 contained potassium gluconate. Drug applications were made with multibarrel pipette $(A, B)$ or flow tube $(C)$. 
Additional evidence that THA activates a transporter current and not a ligand-gated channel is suggested by the current-voltage relationship of THA currents. Figure $4 A$ shows that currents induced by $50 \mu \mathrm{M}$ THA remained inward at a holding potential of $+20 \mathrm{mV}$, whereas responses to $50 \mu \mathrm{M}$ kainate in the same cell were outward at $+20 \mathrm{mV}$. Similar results were observed in two other glia. The inability to reverse THA currents at positive potentials is consistent with the behavior of glutamate transporter currents in Müller cells (Barbour et al., 1991), type I cerebellar astrocytes (Wyllie et al., 1991), and non-native cells expressing rccombinant transportcrs (Klockner ct al., 1993). This behavior, however, is inconsistent with a recently described cerebellar transporter that behaves as a chloride conductor (Fairman et al., 1995). Currents from this cloned transporter show reversal potentials near the chloride equilibrium potential which, with the solutions used in our study, is near $-70 \mathrm{mV}$.

Also inconsistent with THA acting at a ligand-gated glutamate receptor is the inability of lithium to support THA currents (Fig. $4 B$ ). Replacing extracellular sodium with lithium abolished THA responses $(n-5$; Fig. $4 B$ ). In contrast, replacing lithium with sodium reduced glial currents in response to $1 \mathrm{~mm}$ kainate by only $-8 \pm 3 \%(n=3$; data not shown), which is consistent with the ability of lithium to permeate AMPA receptors (Wyllie et al., 1991; Tong and Jahr, 1994a). Lithium substitution alone caused a reversible inward current in glia of $-23 \pm 9 \mathrm{pA}(n=5)$. It is unknown whether this inward current was related to glutamate transporter function, and the current induced by lithium alone was not investigated further. Finally, the dose-response relationship of THA currents exhibited an $\mathrm{EC}_{50}$ of $4 \mu \mathrm{M}$ (Fig. $4 \mathrm{C}$ ), which is consistent with $\mathrm{EC}_{50}$ values in the low micromolar range for THA acting at recombinant transporters (Arriza et al., 1994; Klockner et al., 1994).

Responses to near-maximal concentrations of THA were much smaller than responses to ionotropic receptor agonists. In a sample of 20 glial microislands, $1 \mathrm{~mm}$ kainate generated an average current of $-1.7 \pm 0.2 \mathrm{nA}$. These currents were $83 \pm 24$ times larger than the average current of $-40 \pm 8 \mathrm{pA}$ produced by THA $(50 \mu \mathrm{M})$ applications to the same microislands (Fig. 5A1,A2). Although the difference in amplitude between responses to high concentrations of the selective agonists THA and kainate suggests a larger ionotropic receptor contribution to high concentrations of glutamate, the comparison could be complicated if the relative efficacies of THA and kainate were very different. To address more directly the question of the relative contributions of uptake and receptor channels to exogenous glutamate responses, we assessed the effect of the non-NMDA receptor antagonists on currents elicited by $1 \mathrm{~mm}$ glutamate, a concentration that should maximally stimulate glutamate transport and near-maximally stimulate AMPA receptors (Fig. 5B). The noncompetitive antagonist GYKI-52466 (100 $\mu \mathrm{M})$ (Zorumski et al., 1993) reduced the peak response to $1 \mathrm{~mm}$ glutamate by $-84 \pm 2 \%$ and reduced the steady-state component of the glutamate response by $-70 \pm 5 \%$ ( $n=7, p<0.02$ compared with peak depression; Fig. $5 B$ ). The competitive AMPA receptor antagonist NBQX $(20 \mu \mathrm{M})$ reduced peak glutamate currents in glia by $-94 \%$ and the steady-state component by $-62 \%(n=2)$. Neither GYKI-52466 $(100 \mu \mathrm{M})$ nor NBQX $(20 \mu \mathrm{M})$ had reliable effects on THA-induced currents $(-8$ $\pm 4 \%, n=10$ for GYKI-52466, Fig. $5 C ; 0 \pm 8 \%, n=4$ for NBQX), indicating that these antagonists do not interfere with transporter function.

The severe depression of both peak and steady-state glutamate currents by non-NMDA receptor antagonists confirms that

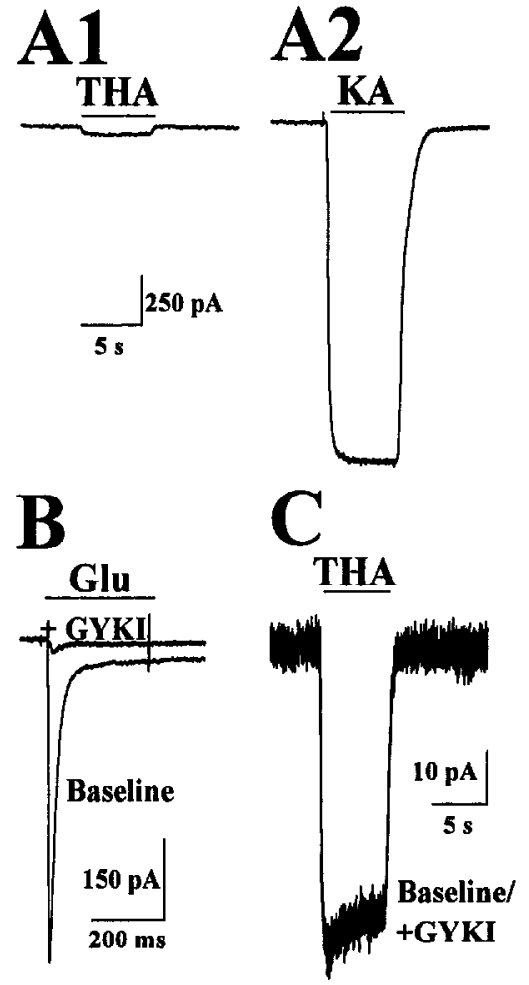

Figure 5. At near-maximal concentrations of glutamate and glutamate agonists, AMPA receptors dominate glial responses. $A$, The left panel $(A l)$ shows a response to $50 \mu \mathrm{M}$ THA, and the right panel $(A 2)$ shows a response to $1 \mathrm{~mm}$ kainate in the same glial cell. $B$, Responses to $1 \mathrm{~mm}$ glutamate before and after treatment with $100 \mu \mathrm{M}$ GYKI-52466. $C$, Effect of $100 \mu \mathrm{M}$ GYKI-52466 on currents induced by THA $(50 \mu \mathrm{M})$. For all experiments, the whole-cell pipette contained potassium gluconate. Drugs were applied by multibarrel pipette in $A$ and $C$ and by flow tube in $B$.

AMPA receptors dominate glial responses to high glutamate concentrations, and the smaller depression of steady-state glutamate responses by GYKI-52466 is consistent with the idea that transporter currents also contribute to glutamate currents in glia. The failure of high concentrations of AMPA receptor antagonists to block ionotropic responses completely precluded accurate measurements of the uptake component of glutamate-induced glial currents. Because of the overwhelming contribution of ionotropic receptors to glial glutamate responses, even a $1-10 \%$ residual steady-state ionotropic current in the presence of antagonists would contribute significantly to measured current amplitudes. Nevertheless, we did attempt to estimate the glial glutamate dose-response relationship for uptake currents by measuring steady-state glutamate currents in the presence of $100 \mu \mathrm{M} \mathrm{GYKI}$ $\mathbf{5 2 4 6 6}$ (higher concentrations were impractical because of solubility) and various concentrations of glutamate. Under these conditions, glutamate activated currents with an $\mathrm{EC}_{50}$ of $19 \mu \mathrm{M}$, which is similar to reported $\mathrm{EC}_{50}$ values for uptake currents generated by glutamate (Klockner et al., 1993) but is also similar to our estimate of steady-state ionotropic responses $(15 \mu \mathrm{M})$.

Given the contributions of AMPA receptors and glutamate transporters to glial currents in response to applications of exogenous glutamate analogs, it is of interest to characterize glial responses to neuronal glutamate release. Electron microscopy of single-neuron excitatory microislands in which the neuron had heen filled with biocytin revealed that neurites often lay at the glia-culture interface. However, in many cases, especially on 

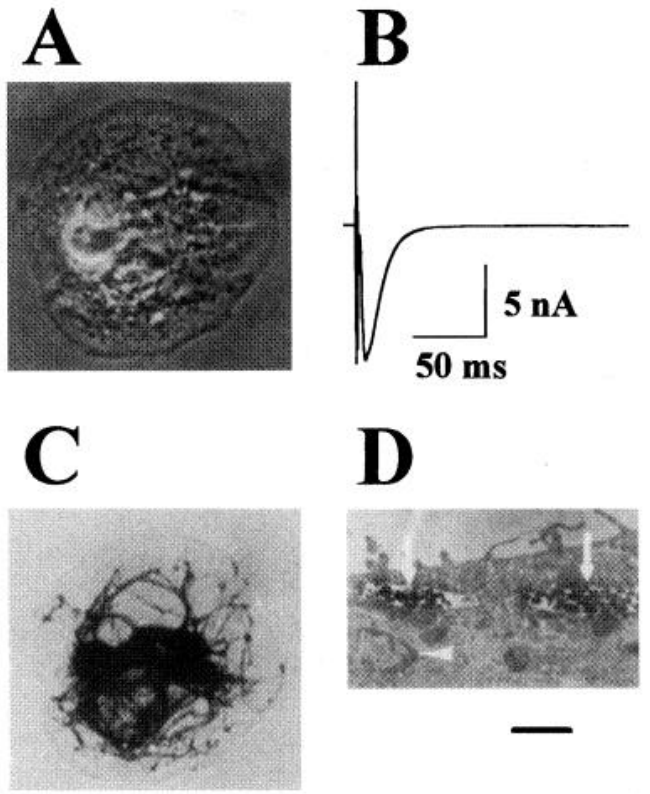

Figure 6. Physical interactions between neurons and glia in microcultures. A, The phase contrast photomicrograph shows an example of a microculture after $5 \mathrm{~min}$ of whole-cell recording from the neuron with a pipette solution containing $0.2 \%$ biocytin. $B$, Excitatory autaptic response recorded from the neuron in the microculture shown in $A$. In this figure, the current transients associated with autaptic stimulation have been preserved. In subsequent figures, the transients have been blanked. $C$, The bright-field photomicrograph shows the microculture from $A$ after fixation and visualization of the biocytin. Note the presence of many neurites not evident in the phase contrast photomicrograph in $A$. D. An electron photomicrograph from a thin section of the microculture (cut perpendicular to the bottom of the culture dish) reveals two groups of biocytinlabeled processes (arrows) enveloped by unlabeled glial appendages. The arrowhead points to a glial nucleus. Scale bar: $21 \mu \mathrm{m}$ for $A$ and $C ; 1.3 \mu \mathrm{m}$ for $D$.

those microislands where processes were not readily visible with phase contrast microscopy, neurites were enveloped by unlabeled glial elements (Fig. 6). In studies of electrophysiological interactions between glia and neurons, some selection bias was exercised toward microislands that, under phase contrast microscopy, appeared to have neurites buried in the glial underlayer (Fig. 6A) because this situation more accurately reflects the case in situ, in which glial elements often surround dendrites and synaptic contacts (Peters et al., 1991).

Electrophysiological responses of glia to excitatory neuronal stimulation were obtained with dual recordings from solitary neurons and underlying glia. In most cases, neuronal stimulation resulted in an inward glial current at $-70 \mathrm{mV}$. Previously, we found little or no evidence for a contribution of AMPA receptors in glial responses to neuronal stimulation (Mennerick and Zorumski, 1994). In light of the large AMPA component of responses to exogenous glutamate, we re-examined this issue in a larger sample of neuron-glia pairs. To assess the contribution of AMPA receptors to glial responses, we used the AMPA receptor antagonist NBQX (1-20 $\mu \mathrm{M})$. Because we observed similar effects on glial currents with concentrations $\geq 1 \mu \mathrm{M}$ NBQX (see below), results using 1-20 $\mu \mathrm{M}$ NBQX were pooled. In 32 pairs treated with NBQX, glial responses were inhibited by $-20 \pm 5 \%$ (range: no effect to $-90 \%$ ). Figure 7 shows an example of a neuron-glia pair in which NBQX caused a small but reliable depression of the glial response while abolishing the neuronal response. Addition of THA plus NBQX caused a much larger depression of the glial
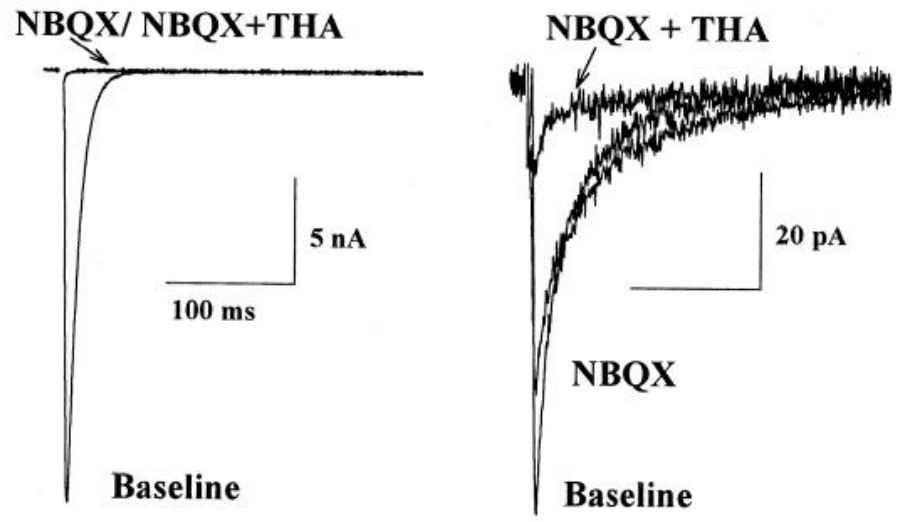

Figure 7. Responses of glia to stimulation of excitatory neurons are weakly sensitive to AMPA receptor blockade. The left panel depicts the autaptic response of a neuron. The right panel shows the accompanying responses of an underlying glial microisland. The NBQX concentration was $1 \mu \mathrm{M}$, and the THA concentration was $50 \mu \mathrm{M}$. The transients associated with neuronal stimulation were blanked.

response $(-82 \pm 9 \%$ of the current remaining after NBQX treatment, $n=6$ ), which is consistent with a strong contribution of electrogenic glutamate uptake to glial currents (Mennerick and Zorumski, 1994). Often even the combination of NBQX and THA did not abolish glial responses (Fig. 7). This residual current is explored in more detail below. In contrast to glial currents, neuronal autaptic responses were abolished with the addition of NBQX alone (Fig. 7).

If AMPA receptors contribute to glial responses, one would also expect $\mathrm{CYZ}$ to potentiate glial responses. Consistent with this prediction, glial currents exhibiting an NBQX-sensitive component were potentiated by CYZ (Fig. 8). Glial currents on average showed nearly a tripling in amplitude with CYZ application (from $-42 \pm 20$ to $-121 \pm 81 \mathrm{pA}, n=10$ pairs). However, CYZ clearly potentiated glial responses only in those cells exhibiting an NBQX-sensitive component in baseline conditions (Fig. 8A,B). The NBQX sensitivity of the CYZ potentiation suggests that the potentiation was via AMPA receptors and not via an effect on glutamate uptake. Consistent with this interpretation, CYZ did not affect glial currents induced by $50 \mu \mathrm{M}$ THA application $(+1 \pm$ $3 \%$ change, $n=9$ ). In contrast to glial responses, all neuronal autaptic responses were potentiated by CYZ (from $-6.7 \pm 1.7$ to $-9.2 \pm 1.8 \mathrm{nA}, n=10$ pairs; Fig. $8 A, B)$.

Given the similarity of AMPA receptor-mediated neuronal and glial currents in response to exogenous agonists, it is of interest to compare the kinetics of the AMPA receptor-mediated currents in the two cell types in response to endogenously released glutamate. We examined the kinetics of the NBQX-sensitive component of glial and neuronal responses in the subset of pairs in which the NBQX-sensitive component of glial currents was $>10 \mathrm{pA}$ (arbitrarily chosen to provide resolution for exponential fitting). Figure 9 shows the result of subtracting the residual current in the presence NBQX from the current observed in the absence of NBQX in both the neuron and the glial cell from Figure 8. Glial and neuronal NBQX-sensitive currents were scaled and superimposed for display to facilitate time course comparisons. It can be appreciated that the smaller NBQX-sensitive glial current rises and decays more slowly than the neuronal autaptic NBQXsensitive component. In the 10 pairs of recordings analyzed, the NBQX-sensitive component of glial currents decayed with a time constant of $32 \pm 7 \mathrm{msec}$, whereas autaptic responses from the 


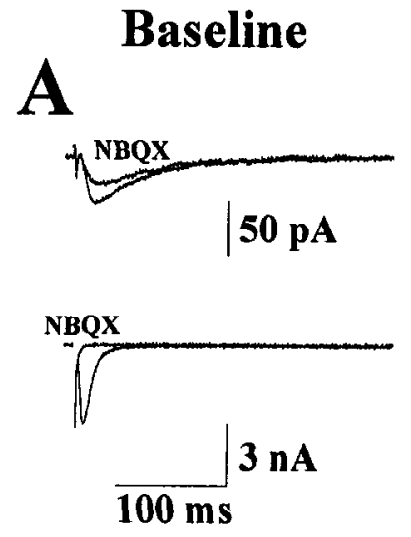

B
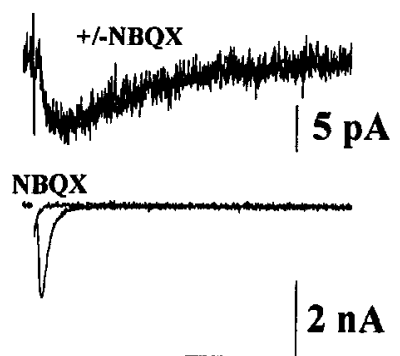

$100 \mathrm{~ms}$

Figure 8. The NBQX-sensitive component of glial responses is potentiated by CYZ. The top traces in each panel represent glial currents; the bottom traces represent neuronal autaptic responses. The left panels depict the effect of NBQX $(2 \mu \mathrm{M})$ on autaptic and glial responses before treatment with $50 \mu \mathrm{M} \mathrm{CYZ}$. The right traces show the effects of NBQX after addition of $C Y Z$ to the extracellular solution. $A$, An example of a neuronglia pair in which NBQX clearly decreased glial currents in the baseline condition; the glial current (as well as the neuronal autaptic current) was potentiated by CYZ. $B$, An example of another neuron-glia pair from the same plating, in which there was no NBQX-sensitive component of glial responses. Glial responses were not potentiated by CYZ.

same pairs decayed with a time constant of $8.7 \pm 0.9 \mathrm{msec}(p<$ 0.05 , independent two-tailed $t$ test). Little is known about the electrotonic structure of glial microislands. Therefore, it is possible that the slower kinetics of glial currents reflects electrotonic filtering of the AMPA receptor-mediated currents. However, the slow kinetics is also consistent with diffusion of glutamate to glial receptors located some distance from the synaptic cleft.

In summary, both AMPA receptors and electrogenic uptake contribute to glial responses to endogenous glutamate released at synapses in culture. Although the contribution of ionotropic reccptors and uptake varics from microculture to microculture, AMPA receptors on average contribute $\sim 20 \%$ to the peak glial response. This contrasts markedly with the contribution of AMPA receptors to glial currents elicited by exogenous applications of high glutamate concentrations (Fig. 6). The contribution of AMPA receptors to glial responses during synaptic events also helps explain the inability of uptake inhibitors to abolish glial responses in a previous study (Mennerick and Zorumski, 1994). However, as depicted in Figure 7, the combination of uptake inhibitors and receptor antagonists often still did not abolish glial responses.

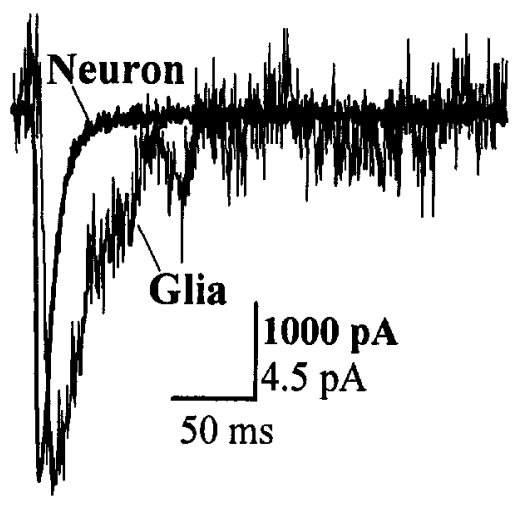

Figure 9. The NBQX-sensitive component of glial responses exhibits a slower rise and decay than the neuronal aulaptic current. The thick trace represents the NBQX-sensitive component of the neuron's response to stimulation (the AMPA receptor-mediated autaptic response) from the left panel of Figure 6 . The thin trace shows the NBQX-sensitive component of the glial response from the same dual recording. In both cases, the NBQX-sensitive components were obtained by digitally subtracting the residual current in the presence of NBQX from the baseline current.

A detectable residual glial current was seen in the presence of extracellular lithium (total replacement for sodium) to abolish uptake and, in the presence of $1 \mu \mathrm{M}$ NBQX, to block AMPA receptors in 15 of 20 pairs. In these 15 pairs, the residual current had an amplitude of $-13.4 \pm 2.2 \mathrm{pA}$. The residual glial response could be attributable to residual uptake or to ionotropic currents not blocked by inhibitors. The current did not appear to be attributable to a remaining contribution of AMPA receptors because $20 \mu \mathrm{M}$ NBQX did not reduce currents further beyond the depression achieved by $1 \mu \mathrm{M} \operatorname{NBQX}(p>0.7$, paired $t$ test, $n=$ $9)$. It is possible that part of the residual response is attributable to residual glutamate uptake because $100 \mu \mathrm{M}$ cadmium, which blocks neuronal calcium influx and abolishes neuronal autaptic responses ( $n=5$ neurons), reduced the residual current by approximately half (from $-24.9 \pm 3.1$ to $-12.5 \pm 1.4 \mathrm{pA}$ ) in three pairs with large residual responses (Fig. 10) and to below detectable levels in three additional cells with smaller residual currents $(-8.9 \pm 0.8 \mathrm{pA})$. However, because cadmium was unable to abolish the glial response in all cells, there likely is a component of glial responses to neuronal stimulation that is unrelated to calcium-dependent transmilter release. A similar residual response has been observed in normal sodium-containing media lacking added calcium (Mennerick and Zorumski, 1994).

Glia have been proposed to buffer potassium released by neurons during action potentials (Karwoski et al., 1989), and depolarizations of glia caused by elevations of extracellular potassium have been recorded in response to neuronal activity (Orkand et al., 1966; Ransom and Goldring, 1973). To explore whether the residual microculture glial current was caused by a transient elevation of extracellular potassium, we blocked neuronal potassium efflux with a combination of tetraethylammonium and 4-aminopyridine. Control experiments showed that this treatment dramatically prolonged neuronal action potentials, indicating an effective reduction in potassium efflux. Blocking neuronal potassium efflux had no effect on the residual glial current recorded in $100 \mu \mathrm{M}$ cadmium (Fig. 10). Tetrodotoxin has been shown to abolish aulaptic responses evoked with the voltage-step stimulation protocol used in the present study, presumably by blocking an action potential in the unclamped axon of the neuron (Bekkers and Stevens, 1991). To determine whether the residual glial cur- 


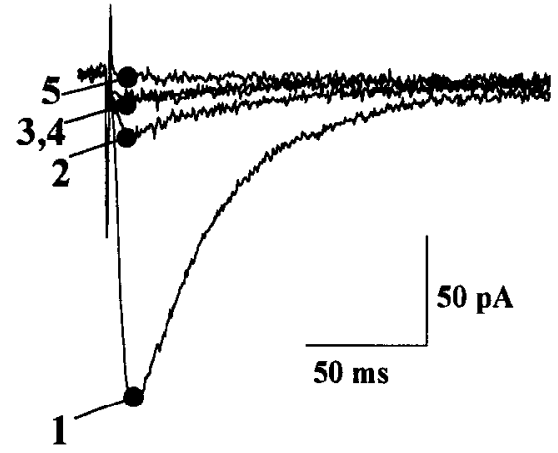

Figure 10. A small component of many glial responses to neuronal activity does not depend on calcium-dependent transmitter release and is not attributable to potassium buffering. The traces represent glial responses to neuronal stimulation (data not shown). The traces are labeled with numbers corresponding to various experimental treatments. Trace 1, The response in baseline $\mathrm{NaCl}$ extracellular solution. Traces 2-5 were all obtained in $\mathrm{LiCl}$ solution (total substitution for $\mathrm{NaCl}$ ) containing $2 \mu \mathrm{M}$ NBQX. Trace 2, Response in $\mathrm{LiCl}$ and NBQX only. Trace 3, Cadmium $(100 \mu \mathrm{M})$ was added to the extraccllular solution to block ncuronal calcium influx. Trace 4, In addition to cadmium, $10 \mathrm{~mm}$ tetraethylammonium and $100 \mu \mathrm{M}$ 4-aminopyridine were added to block potassium efflux from the neuron after stimulation. Trace 5, $1 \mu \mathrm{M}$ tetrodotoxin was added to the $\mathrm{LiCl}$ solution; no potassium or calcium channel blockers were added.

rent was mediated by neuronal activity, we treated microcultures with $1 \mu \mathrm{M}$ tetrodotoxin to abolish the axonal action potential. Tetrodotoxin abolished the glial response (Fig. 10). Results similar to those in Figure 10 were also observed with the other two dual recordings in which a residual glial current was detected in the presence of cadmium.

Given the rather small amplitude of glial currents $(<100 \mathrm{pA})$ and the generally low input resistance of the glial microislands, it is unclear whether glia would be depolarized significantly by neuronal stimulation. We examined this issue directly by recording from glia under current clamp while stimulating an overlying neuron in the usual manner. Figure 11 shows voltage-clamp and current-clamp records from a glial cell during neuronal stimulation. In four dual recordings, glial currents (recorded at $-70 \mathrm{mV}$ ) averaged $-91 \pm 38 \mathrm{pA}$ (range -43 to $-203 \mathrm{pA}$ ). When these same microcultures were current-clamped, depolarizations of 4.2 $\pm 2.2 \mathrm{mV}$ (range $1.3-10.7 \mathrm{mV}$ ) resulted from a resting potential ( 0 injected current) of $-62 \pm 4 \mathrm{mV}$.

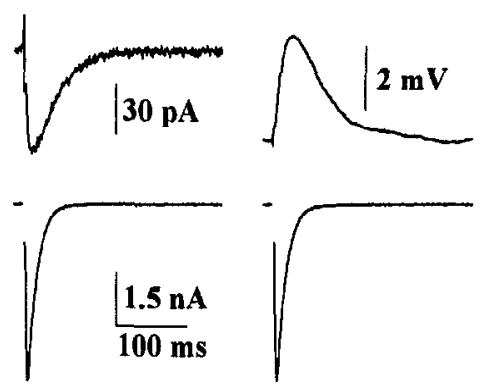

Figure 11. Effects on glial membrane potential of neuronal activity. The top panels represent glial responses, and the bottom panels represent neuronal autaptic currents. The glial trace in the left panel shows the average of three responses recorded in voltage clamp $(-70 \mathrm{mV})$. The glial traces in the right panel show the depolarization from a resting potential of $-54 \mathrm{mV}$ induced by neuronal stimulation.

\section{DISCUSSION}

Microcultures offer several attractive features for exploring neuronal-glial interactions. Classically, neuronal transmitter effects on glia have becn studicd in invertebrates, where the large size of cellular elements facilitates experimental observations (Liebermann et al., 1994). With microcultures of vertebrate neurons, the concentration of a large number of synaptic contacts from a single neuron into the small area of the microculture partly compensates for the small biological signals arising from small, individual cellular elements (e.g., synapses and axons) of vertebrate neurons. Additionally, cell types are distinguished easily using visual criteria in primary cultures. Finally, autaptic responses offer the ability to study presynaptic and postsynaptic neuronal function while monitoring glia. These features make microcultures an attractive experimental model for studying neuronal-glial interactions and allow experiments to be performed that would be very difficult or impossible to perform in situ.

This study extends previous work from this laboratory examining electrophysiological interactions between glia and neurons in hippocampal microcultures. We have compared the effects on glial membrane currents of exogenously applied glutamate agonists with the effects of synaptically released glutamate to understand better the interplay between neuronal signaling and glial function. To our knowledge, this report is the first to show glial ionotropic receptor activation by a synaptically released transmitter.

One conclusion from this work is that although ionotropic AMPA receptors dominate glial responses to low millimolar concentrations of glutamate, AMPA receptors play, on average, a minor role in mediating responses to synaptically released glutamate. The dominant ionotropic currents likely are a reason for the failure to detect a transporter component in glial glutamate responses in some studies (Sontheimer et al., 1988). However, in a study of young cerebellar type I astrocytes in culture, exogenous glutamate responses were dominated by large transporter currents with little or no contribution from ionotropic receptors (Wyllie et al., 1991). This suggests that the relative contribution of transporters and receptors to exogenous glutamate responses varies with culture conditions and/or with the brain region of study.

The difference in contributions of transporters and receptors to responses mediated by exngenous and endogenous glutamate in the present study likely reflects that concentrations of glutamate reaching the glial membrane are substantially lower than concentrations in the synaptic cleft, which are thought to exceed briefly $1 \mathrm{~mm}$ (Clements et al., 1992). The lower concentration of glutamate-reaching glia would allow the higher-affinity glutamate transporters to dominate responses to endogenous glutamate. Additionally, cultured glial cells may target transporters to synaptic regions, as they appear to do in situ (Rothstein et al., 1994), causing responses to synaptic glutamate to be dominated by glutamate uptake.

Although small in absolute amplitude, the electrogenic uptake component of glial responses can have functional consequences (Mennerick and Zorumski, 1994, 1995), suggesting that a substantial fraction of neuronally released glutamate reaches glial transporters. From data obtained in this study, combined with recent estimates of the amount of glutamate released during a quantal synaptic event, one can estimate the fraction of glutamate that might be transported by glia after evoked release. In a sample of six neuron-glia pairs treated with THA as in Figure 7, the THA- 
sensitive glial current (obtained by digital subtraction) was $-21 \pm$ $5 \mathrm{pA}$, with a time constant of decay of $47 \pm 7 \mathrm{msec}$. The average charge movement represented by the THA-sensitive component was $1.0 \pm 0.3$ picocoulombs $(\mathrm{pC})$. Assuming one elementary charge translocation on each cycle of the transporter (Barbour et al., 1991), this charge transfer represents the transport of an average of $6 \times 10^{6}$ glutamate molecules per synaptic event.

One can also estimate the number of glutamate molecules released with each evoked synaptic event by estimating the number of transmitter quanta in an evoked response and the number of glutamate molcculcs in a quantum. In the same sample of six neuron-glia pairs treated with THA, the average charge transfer for the neuronal autaptic responses was $81 \pm 33 \mathrm{pC}$. Miniature synaptic events in this preparation have an amplitude of $\sim 10 \mathrm{pA}$ and a time constant of $\sim 3.0 \mathrm{msec}$, suggesting a quantal charge transfer of $0.03 \mathrm{pC}$. It can be estimated, therefore, that the evoked events in this sample had a quantal content of $\sim 2700$. The number of glutamate molecules in a vesicle has been suggested to be $\sim 2000$ (Burger et al., 1989; Clements et al., 1992), leading to an estimate of $5.4 \times 10^{6}$ molecules of glutamate released for an average synaptic event in this sample of cells. Assuming that each transporter binds and transports only one glutamate molecule during a synaptic event, one can also estimate the number of glutamate transporters per release site to be $\sim 2200$ by dividing the elementary charge transfer in glial responses by the quantal content estimate of autaptic responses.

Surprisingly, these estimates suggest that all of the glutamate released is transported and that little transmitter is lost to free diffusion. This would not be necessarily incompatible with the idea that clearance from the synaptic cleft by transport is slower than diffusion (Eccles and Jaeger, 1958; Tong and Jahr, 1994a; Mennerick and Zorumski, 1995); diffusion could be primarily responsible for transmitter clearance from the vicinity of neuronal synaptic receptors, whereas rapid binding of transmitter by large numbers of nearby transporters (see calculations above) (Tong and Jahr, 1994a) would prevent glutamate from being lost to the system as a whole. Alternatively, more glutamate might be released than is apparent from postsynaptic current measurements. This could happen if multiple quanta are released from a single release site during evoked release, but with full postsynaptic receptor occupancy occurring after the release of a single quantum (Tong and Jahr, 1994b). The "spare" quanta released might be transported but would not be detected by postsynaptic receptors, leading in the above calculations to an inflated estimate of the fraction of released glutamate that is transported. Conversely, previous work from this laboratory has suggested that there is significant cross-talk between synapses at microculture synapses (Mennerick and Zorumski, 1995). If cooperative actions of quanta released from nearby sites prolong evoked autaptic currents beyond the time course of a single quantal EPSC, the estimate of quantal content above may be inflated and an even higher fraction of transporter capture would be suggested.

Classical studies of neuronal-glial interactions have suggested a large role for stimulation-induced rises in extracellular potassium in depolarizing glia (Orkand et al., 1966; Ransom and Goldring, 1973). In contrast, we failed to find a role for neuronal potassium release in microculture glial currents. Because all previous studies have relied on repetitive stimulation of fiber tracts to demonstrate glial depolarizations by potassium, it is likely that the single stimulus to single neurons used in the present study was not sufficient to induce this form of glial response to neuronal stimulation.
Nevertheless, there appears to be a small component of glial responses to neuronal activity in microcultures that is not related to calcium-dependent transmitter release. Calcium-independent release of substances such as glutamate and adenosine from axons has been suggested in other preparations (Chiu and Kriegler, 1994), so these agents remain candidates for the small residual component of glial responses recorded in the present study. Because of the small amplitude of this component, it is likely that conditions will have to be found that augment the response for this component to be studied in more detail.

The sum of the several components of glial responses to neuronal stimulation was able to depolarize cells by several millivolts. However, it is unclear what signaling rolc thesc depolarizations have in nonspiking glia. It is possible that repeated stimuli delivered to neurons provide sufficient depolarization of glia to decrease the rate of glutamate uptake (Barbour et al., 1991) or actually to increase ambient glutamate levels through reverse glutamate uptake (Szatkowski et al., 1990). It is also possible that repeated stimuli allow the opening of voltage-gated channels, which many glia are known to possess (Sontheimer, 1994). Additionally, glial gap junctions may be modulated by membrane depolarizations (Enkvist and McCarthy, 1994) in response to neuronal stimulation.

\section{REFERENCES}

Anderson CR, Stevens CF (1973) Voltage clamp analysis of acelylcholine produced end-plate current fluctuations at frog neuromuscular junction. J Physiol (Lond) 235:655-691.

Arriza JL, Fairman WA, Wadiche JI, Murdoch GH, Kavanaugh MP, Amara SG (1994) Functional comparisons of three glutamate transporter subtypes cloned from human motor cortex. J Neurosci $14: 5559-5569$.

Barbour B, Brew H, Attwell D (1991) Electrogenic uptake of glutamate and aspartate into glial cells isolated from the salamander (Ambystoma) retina. J Physiol (Lond) 436:169-193.

Bekkers JM, Stevens CF (1991) Excitatory and inhibitory autaptic currents in isolated hippocampal neurons maintained in cell culture. Proc Natl Acad Sci USA 88:7834-7838.

Belliveau DJ, Naus CCG (1994) Cortical type 2 astrocytes are not dye coupled nor do they express the major gap junction genes found in the central nervous system. Glia 12:24-34.

Burger PM, Mehl E, Cameron PL, Maycox PR, Maumert M, Lottspeich F, De Camilli P, Jahn R (1989) Synaptic vesicles immunoisolated from rat cerebral cortex contain high levels of glutamate. Neuron 3:715-720.

Burnashev N, Khodorova A, Jonas P, Helm PJ, Wisden W, Monyer H, Seeburg PH, Sakmann B (1992) Calcium-permeable AMPA-kainate receptors in fusiform cerebellar glial cells. Science 256:1566-1570.

Chiu SY, Kriegler S (1994) Neurotransmitter-mediated signaling between axons and glial cells. Glia 11:191-200.

Clements JD, Lester RA, Tong G, Jahr CE, Westbrook GL (1992) The time course of glutamate in the synaptic cleft. Science 258:1498-1501.

Cornell-Bell AH, Finkbeiner SM, Cooper MS, Smith SJ (1990) Glutamate induces calcium waves in cultured astrocytes: long-range glial signaling. Science 247:470-473.

Dani JW, Chernjavsky A, Smith SJ (1992) Neuronal activity triggers calcium waves in hippocampal astrocyte networks. Ncuron 8:429-440.

Eccles JC, Jaeger JC (1958) The relationship between the mode of operation and the dimensions of the junctional regions at synapses and motor end-organs. Proc R Soc Lond [Biol] 148:38-56.

Enkvist MO, McCarthy KD (1994) Astroglial gap junction communication is increased by treatment with either glutamate or high $\mathrm{K}^{+}$concentration. J Neurochem 62:489-495.

Fairman WA, Vandenberg RJ, Arriza JL, Kavanaugh MP, Amara SG (1995) An excitatory amino-acid transporter with properties of a ligand-gated chloride channel. Nature 375:599-603.

Furshpan EJ, Landis SC, Matsumoto SG, Potter DD (1986) Synaptic functions in rat sympathetic neurons in microcultures. I. Sccrction of norepinephrine and acetylcholine. J Neurosci 6:1061-1079. 
Karwoski CJ, Lu HK, Newman EA (1989) Spatial buffering of lightevoked potassium increases by retinal Müller (glial) cells. Science 244:578-580.

Keinanen K, Wisden W, Sommer B, Werner P, Herb A, Verdoorn TA, Sakmann B, Seeburg PH (1990) A family of AMPA-sclective glutamate receptors. Science 249:556-560.

Klockner U, Storck T, Conradt M, Stoffel W (1993) Electrogenic Lglutamate uptake in Xenopus laevis oocytes expressing a cloned rat brain L-glutamate/L-aspartate transporter (GLAST-1). J Biol Chem 268:14594-14596.

Klockner U, Storck T, Conradt M, Stoffel W (1994) Functional properties and substrate specificity of the cloned L-glutamate/L-aspartate transporter GLAST-1 from rat brain expressed in Xenopus oocytes. J Neurosci 14:5759-5765.

Liebermann EM, Hargittai PT, Grossfeld RM (1994) Electrophysiological and metabolic interactions between axons and glia in crayfish and squid. Prog Neurobiol 44:333-376.

Mennerick S, Que J, Benz A, Zorumski CF (1995) Passive and synaptic properties of neurons grown in microcultures and in mass cultures. J Neurophysiol 73:320-332.

Mennerick S, Zorumski CF (1994) Glial contributions to excitatory neurotransmission in cultured hippocampal cells. Nature 368:59-62.

Mennerick S, Zorumski CF (1995) Presynaptic influence upon the time course of fast excitatory synaptic currents in cultured hippocampal neurons. J Neurosci 15:3178-3192.

Müller T, Grosche J, Ohlemeyer C, Kettenmann H (1993) NMDA-activated currents in Bergmann glial cells. NeuroReport 4:671-674.

Müller T, Moller T, Berger T, Schnitzer J, Kettenmann H (1992) Calcium entry through kainate receptors and resulting potassium-channel blockade in Bergmann glial cells. Science 256:1563-1566.

Murphy TH, Blatter LA, Wier WG, Baraban JM (1993) Rapid communication between neurons and astrocytes in primary cortical cultures. J Neurosci 13:2672-2679.

Orkand RK, Nicholls JG, Kuffler SW (1966) Effect of nerve impulses on the membrane potential of glial cells in the central nervous system of amphibia. J Neurophysiol 29:788-806.

Partin KM, Patneau DK, Mayer ML (1994) Cyclothiazide differentially modulates desensitization of $\alpha$-amino-3-hydroxy-5-methyl-4-isoxazolepropionic acid receptor splice variants. Mol Pharmacol 46:129-138.

Partin KM, Patneau DK, Winters CA, Mayer ML, Buonanno A (1993) Selective modulation of desensitization at AMPA versus kainate receptors by cyclothiazide and concanavalin A. Neuron 11:1069-1082.
Peters A, Palay SL, Webster HD (1991) Synapses. In: The fine structure of the nervous system, pp 138-211. New York: Oxford UP.

Ransom BR, Goldring S (1973) Slow depolarizations in cells presumed to be glia in the cerebral cortex of the cat. J Neurophysiol 36:869-878.

Rothstcin JD, Martin L, Levcy AI, Dykcs-Hobcrg M, Jin L, Wu D, Nash N, Kuncl RW (1994) Localization of neuronal and glial glutamate transporters. Neuron 13:713-725.

Sontheimer H (1994) Voltage-dependent ion channels in glial cells. Glia $11: 156-172$.

Sontheimer H, Kettenmann H, Backus KH, Schachner M (1988) Glutamate opens $\mathrm{Na}^{+} / \mathrm{K}^{+}$channels in cultured astrocytes. Glia 1:328-336.

Stephens GJ, Djamgoz MBA, Wilkin GP (1993) A patch clamp study of excitatory amino acid effects on cortical astrocyte subtypes in culture. Receptors Channels 1:39-52.

Szatkowski M, Barbour B, Attwell D (1990) Non-vesicular release of glutamate from glial cells by reversed electrogenic glutamate uptake. Nature 348:443-446.

Thio LL, Clifford DB, Zorumski CF (1991) Characterization of quisqualate receptor desensitization in cultured postnatal rat hippocampal neurons. J Neurosci 11:3430-3441.

Thio LL, Clifford DB, Zorumski CF (1992) Blockade of ionotropic quisqualate receptor desensitization by wheat germ agglutinin in cultured postnatal rat hippocampal neurons. J Neurophysiol 68:1917-1929.

Tong G, Jahr CE (1994a) Block of glutamate transporters potentiates postsynaptic excitation. Neuron 13:1195-1203.

Tong G, Jahr CE (1994b) Multivesicular release from excitatory synapses of cultured hippocampal neurons. Neuron 12:51-59.

Usowicz MM, Gallo V, Cull-Candy SG (1989) Multiple conductance channels in type-2 cerebellar astrocytes activated by excitatory amino acids. Nature 339:380-383.

Verdoorn TA, Burnashev N, Monyer H, Seeburg PH, Sakmann B (1991) Structural determinants of ion flow through recombinant glutamate receptor channels. Science 252:1715-1718.

Wyllie DJ, Mathie A, Symonds CJ, Cull-Candy SG (1991) Activation of glutamate receptors and glutamate uptake in identified macroglial cells in rat cerebellar cultures. J Physiol (Lond) 432:235-258.

Yamada KA, Tang CM (1993) Benzothiadiazides inhibit rapid glutamate receptor desensitization and enhance glutamatergic synaptic currents. J Neurosci 13:3904-3915.

Zorumski CF, Yamada KA, Price MT, Olney JW (1993) A benzodiazepine recognition site associated with the non-NMDA glutamate receptor. Neuron 10:61-67. 